\title{
DIREITO À MIGRAÇÃO E A FUNÇÃO COLONIAL MODERNA DO CONTROLE DE FRONTEIRAS
}

\author{
RIGHT TO MIGRATION AND THE COLONIAL MODERN FUNCTION OF BORDER \\ CONTROL
}

\author{
Débora Ferrazzo ${ }^{1}$ \\ Universidade do Extremo Sul Catarinense \\ Maria de Fatima S. Wolkmer ${ }^{2}$ \\ Universidade do Extremo Sul Catarinense \\ Daniel Raizer Fiamoncini ${ }^{3}$ \\ Universidade do Extremo Sul Catarinense
}

\begin{abstract}
Resumo:
Um dos campos mais sensíveis à globalização é o das fronteiras entre os Estados-nação, cada vez mais acessíveis às migrações, mas também cada vez mais controversos em função do controle de entrada e saída. Os conceitos migração e soberania frequentemente são contrapostos, comportando diversas perspectivas, entretanto há uma constante subjacente em tais debates: a função colonial cumprida pelas fronteiras internacionais e pelo controle de migrações, reforçada pela produção teórica que difunde de maneiras mais ou menos sutis os paradigmas eurocêntricos. Tal percepção enseja a necessidade de buscar aportes descoloniais para aprofundar a compreensão do aparente paradoxo entre migração e soberania. Para tanto, propõe-se adoção de método dedutivo de abordagem, buscando um diálogo interdisciplinar entre teorias descoloniais, com ênfase em contribuições teóricas das áreas do direito, teoria política, ciências sociais e filosofia da libertação, sobre o tema das migrações. Dessa forma, pretende-se demonstrar alguns limites coloniais e quiçá, possíveis contribuições para repensar a relação entre migração, fronteiras internacionais e soberania.
\end{abstract}

Palavras-chave:

Migrações. Fronteiras internacionais. Soberania. Colonialidade. Descolonização.

\begin{abstract}
:
One of the most sensitive fields to globalization is that of the boundaries between States, which are increasingly accessible to migration, but also increasingly controversial over entry and exit control. Therefore, the concepts migration and sovereignty are often opposed, with different perspectives, however, there is an underlying constant in such debates: the colonial function fulfilled by international borders and the control of migration, based on theoretical production, that spreads, in more or less subtle ways, the eurocentric paradigms. Such perception gives rise to the need to seek decolonial contributions to deepen the understanding of the apparent paradox between migration and sovereignty. Therefore, it is proposed to adopt a deductive approach method, seeking an interdisciplinary dialogue between decolonial theories, emphasizing theoretical contributions from the areas such as law, political theory, social sciences and liberation philosophy, on the topic of migrations. In this way, it is
\end{abstract}

\footnotetext{
${ }^{1}$ Doutora em Direito pela Universidade Federal do Paraná (UFPR); Mestra em Direito pela Universidade Federal de Santa Catarina (UFSC). Professora no Curso de Direito da Universidade do Extremo Sul Catarinense (UNESC). Integrante do Núcleo de Estudos e Filosóficos (NEFIL/UFPR) e do Núcleo de Pesquisas em Desenvolvimento Regional (FURB). Pesquisadora no Grupo de Pesquisas em Pensamento Jurídico Crítico Latino-americano (UNESC).

${ }^{2}$ Doutora em Direito pela UFSC. Profa. do Programa de Mestrado em Direitos Humanos e Sociedade da UNESCSC.Integrante do NUPEC - "Núcleo de Estudos em Direitos Humanos e Cidadania" (UNESC). Membro do Projeto de Pesquisa "Em Busca de Novas Gramáticas para os Direitos Humanos: Inovações Sócio-jurídico-políticas na América-latina e África", Edital Universal CNPq, 2017-2019. Igualmente, do Projeto de Pesquisa "O Comum, os Novos Direitos e os Processos Democráticos Emancipatórios", 2018.

${ }^{3}$ Mestrando em Direito pela Universidade do Extremo Sul Catarinense. Graduado em Direito pela Fundação Universidade Regional de Blumenau. Integrante do Grupo de Pesquisas em Pensamento Jurídico Crítico Latinoamericano (UNESC). Advogado.
} 
intended to demonstrate some colonial limits and perhaps possible contributions to rethink the relationship between migration, international borders and sovereignty.

Keywords:

Migrations. International borders. Sovereignty. Coloniality. Decolonization.

\section{INTRODUÇÃO}

O notável avanço nas tecnologias, nos meios de comunicação e transporte, viabilizou a emergência de fenômenos e processos que podem repercutir imediata e simultaneamente em todo o mundo. Essa dinâmica tem sido denominada "globalização" e um dos campos mais sensíveis à globalização é o das fronteiras entre os Estados-nação. Por isso, o debate a respeito de temas como migração e fronteiras assume especial relevância e igual complexidade, visto que as situações ensejadoras da mobilidade humana são as mais diversas, variando desde catástrofes naturais, guerras, refúgios, até o exercício de liberdade de escolha do lugar onde se deseja viver ou, simplesmente, turismo. Ambos os conceitos, em especial quando contrapostos, constituem pauta complexa e urgente tanto para os direitos humanos quanto para as agendas constitucionais dos Estados contemporâneos.

Como consequência de uma gama tão variada de motivações, o debate sobre migrações pode ser delimitado sob vários enfoques distintos. Por outro lado, no que se refere à questão das fronteiras, há uma constante bem visível nos mais diversos debates: o paradoxo imposto pela soberania entre os direitos de entrar e sair de territórios. O que se pretende evidenciar nesse estudo é que há outra constante subjacente em ambos os debates: a função colonial cumprida pelas fronteiras internacionais e pelo controle de migrações, que encontram no aporte teórico sobre o tema abundante reforço, considerando que de formas mais ou menos sutis, as publicações a respeito do tema reforçam os paradigmas eurocêntricos, difundindo um imaginário de superioridade e uma dimensão prescritiva de um "estilo de vida" (euro-norteamericano) ideal, baseado em elementos próprios da modernidade colonizadora, como individualismo, liberdade econômica, meritocracia, entre outros.

Assim, a construção simbólica de um mundo maravilhoso, terra de oportunidades, opera como um horizonte de esperança de vida tanto para refugiados nas mais diversas condições, quanto para pessoas que, sem necessariamente sofrer violações flagrantes em seus direitos humanos e fundamentais, apenas desejam buscar o que passa a ser considerado um ambiente mais favorável ao desenvolvimento econômico e humano.

Entretanto, desde uma perspectiva crítica, em especial a descolonial, há contradições importantes que parecem não ser adequadamente consideradas na produção teórica sobre a 
mobilidade e migração, como, por exemplo, a própria função cumprida pelo discurso do "estilo de vida americano". Acredita-se que esse discurso apoia-se numa lógica perversa, traduzindo uma forma eficaz de controle de subjetividades e reforço ao padrão colonial de poder: ao mesmo tempo em que se revela à humanidade um mundo de liberdade e felicidade onde todos têm oportunidades infinitas, são erguidos muros para proteção e são encarcerados aqueles que têm a audácia de desafiar as fronteiras desse mundo maravilhoso.

Revisar criticamente o debate a respeito das fronteiras e do controle de migrações é fundamental, não apenas enquanto resistência epistemológico-política ao poder e dominação que ambos sustentam, mas também em defesa da diversidade ontológica e cultural que subalternizam e excluem. Em suma, considera-se importante ampliar o debate a partir de perspectivas periféricas, para problematizar a eficácia do direito humano à migração e outros que lhe são conexos.

Para tanto, propõe-se adoção de método dedutivo de abordagem, a partir de uma revisão crítica e interdisciplinar de aportes teóricos advindos especialmente das áreas do direito, teoria política, ciências sociais e filosofia da libertação e de uma revisão de bibliografia no tema das migrações, cujos aportes, conforme se constatou, parecem ser produzidos principalmente nos países anglo-saxões. Essa origem não é apenas geográfica, mas também epistemológica, o que permite identificar uma tendência eurocêntrica em tal produção.

Diante disso, para privilegiar uma interação dialética e problematizadora, pretende-se colocar tais aportes em diálogo com teorias descoloniais, que podem fornecer perspectivas para problematizar e revelar padrões norte-eurocêntricos nos discursos, como o American way of life, a identificação do liberalismo econômico e individualismo como únicas plataformas sólidas para construção de uma "vida boa" e "sociedade democrática", ou ainda a naturalização da hierarquização racial, que tem na "seleção de imigrantes" uma das formas de manifestação - escusada pela soberania, entre outros os conceitos dogmaticamente construídos e significados.

Em certa medida, trata-se de buscar, ou tentar exercitar um estranhamento de algumas construções teóricas que assumem pressupostos (como os citados) como fundamentos axiomáticos, negligenciando a reflexão crítica a respeito de seus efeitos na crise global de mobilidade humana. Dessa forma, pretende-se demonstrar alguns limites coloniais e quiçá, possíveis contribuições para repensar a relação entre migração, fronteiras internacionais e soberania.

A primeira seção apresentará uma breve revisão conceitual de algumas categorias e ideias extraídas do pensamento descolonial, delimitando-as no campo da "modernidade eurocêntrica" e apresentando bases introdutórias para uma reflexão crítica a respeito da função 
das fronteiras e seu controle. A segunda seção apresentará também uma revisão conceitual, mas desde outro ponto de vista: a partir de expressões do "pensamento de centro", buscando apresentar um panorama de como alguns dos principais teóricos atualmente reconhecidos no debate a respeito do direito de migração abordam o tema. A orientação dessa seção segue a aplicação metodológica de Enrique Dussel, que percorre as teorias de "centro" como "mediações", as quais apresentam contribuições importantes, porém, insuficientes para compreender a realidade desde uma perspectiva externa ao sistema. No contexto desse ensaio, essa perspectiva externa (ou periférica) é a condição e posição dos sujeitos e dos povos periféricos que desejam migrar para os países centrais.

Finalmente a terceira seção buscará problematizar, a partir de uma perspectiva descolonial, categorias discutidas na primeira parte, para melhor formular uma crítica das posições e omissões teóricas discutidas na seção intermediária, visto que os ocultamentos e ausências periféricas no debate sobre migração contribuem para os embaraços na efetivação dos direitos humanos e fundamentais em termos de mobilidade internacional e direitos conexos.

\section{FRONTEIRAS INTERNACIONAIS E PODER COLONIAL}

A desafiadora tarefa inicial é delimitar o tempo e o espaço da análise proposta. Para tanto, é necessário identificar o fio condutor que permitirá relacionar as causas e os efeitos do campo a ser problematizado. Nesse sentido, para evidenciar a função colonial exercida pelas fronteiras internacionais e reforçada pelos aportes teóricos a respeito do tema, propõe-se a delimitação desse campo de debate na modernidade (tempo) eurocêntrica (espaço físico e metafísico, com alcance epistemológico). Embora a modernidade abrigue diversas acepções e periodizações, numa perspectiva descolonial, considera-se precisa a formulação de Enrique Dussel (1993), ao identificar no ano de 1492 a "data de nascimento da Modernidade". O autor reconhece um processo precedendo esse momento exato, um processo gestado nas cidades europeias medievais, mas que "nasce", efetivamente, do confronto com o "Outro" (diversidade ontológica que após a conquista, viria a ser subsumida na Totalidade europeia sob a denominação de "latino-americano") e triunfa com o seu controle e encobrimento. A tese de Dussel é importante especialmente porque evidencia a origem do fenômeno do "eurocentrismo", categoria fundamental para o desenvolvimento das reflexões que aqui estão sendo propostas: 
Revista da Faculdade Mineira de Direito | V.24 N.47|

Direito e Democracia na Sociedade Contemporânea

O ano de 1492, segundo nossa tese central, é a data do "nascimento" da Modernidade; embora sua gestação - como o feto - leve um tempo de crescimento intra-uterino. A modernidade originou-se nas cidades européias medievais, livres, centros de enorme criatividade. Mas "nasceu" quando a Europa pôde se confrontar com o seu "Outro" e controlá-lo, vencê-lo, violentá-lo: quando pôde se definir como um "ego" descobridor, conquistador, colonizador da Alteridade constitutiva da própria Modernidade. De qualquer maneira esse Outro não foi "descoberto" como Outro, mas foi "en-coberto" como o "si-mesmo" que a Europa já era desde sempre. De maneira que o 1492 será o momento do "nascimento" da Modernidade de um "mito" de violência sacrifical muito particular, e, ao mesmo tempo, um processo de "en-coberto" do não europeu (DUSSEL, 1993, p. 8).

Pode-se compreender tal processo no diálogo com o historiador mexicano Edmundo O’Gorman (1992, p. 26-28; 31) que trouxe, por ocasião da publicação de sua obra A invenção da América, uma perspectiva minuciosamente fundamentada em fontes históricas, nas quais o autor pesquisou e formulou hipóteses a respeito do impacto provocado pelo encontro entre os continentes. Curiosamente, a descrição do autor tangencia, ainda que de modo não muito explícito, a questão das fronteiras: antes das grandes navegações que permitiram à sociedade europeia transpor suas fronteiras físicas e alcançar o continente latino-americano, o homem europeu era prisioneiro de sua própria racionalidade - teocêntrica, e portanto, conformado com sua condição de sujeito passivo de uma realidade explicada por mitos e pela vontade divina. $\mathrm{O}$ que permite inferir que a transposição física das fronteiras provocou o giro epistemológico, a transformação que inaugura a racionalidade moderna.

É que ao desafiar a natureza e encontrar uma porção desconhecida de terras, o homem inventa o novo continente. A importância dessa inversão de perspectivas fica mais clara diante da tese central de O'Gormam de que não foi o descobrimento, mas sim a invenção da América o que aconteceu. Mais precisamente: Edmundo O’Gorman problematiza a questão, não sobre o como, quando, ou quem teria "descoberto" o continente, mas sim, se a "ideia" de descobrimento é o modo correto de enfrentar a questão.

Foi um momento fundamental para a emancipação humana e para a emergência de uma nova racionalidade em que a humanidade é artífice de sua própria realidade: libertando a ciência, dominando a natureza e desenvolvendo tecnologias. O epicentro desse conjunto de transformações foi o espaço europeu, posteriormente irradiando-se para os Estados Unidos, o que permite falar em eurocentrismo. Dussel (1993, p. 17-25) define o eurocentrismo como um conceito mascarado e sutil, incutido nas epistemologias europeias e norte-americanas e apoiado num instrumento eficaz: a falácia desenvolvimentista, que transita entre diversos campos da ciência e permeia as mais diversas teorias. É uma das bases da modernidade: ontologicamente, os países "subdesenvolvidos" são considerados não modernos. Então a modernidade eurocêntrica é o tempo e o lugar em que todos almejam (ou deveriam almejar) estar. 
A difusão da racionalidade moderna eurocêntrica tem início com as colonizações nos demais continentes, que em seu conjunto são designadas por “colonialismo". Numa perspectiva crítica, Aníbal Quijano $(1992 ; 2000 ; 2005)$ define o colonialismo como a dominação de uns povos sobre os outros, deflagrado por meio do processo de colonização, cuja consequência ainda visível, abrange a classificação e hierarquização social expressa no fenômeno da "colonialidade". Quer dizer que o colonialismo enquanto domínio político direto das metrópoles sobre as colônias teve seu fim histórico, foi rechaçado, mas subsiste na forma do imperialismo. No contraste, o colonialismo era o poder explícito e a colonialidade uma das marcas do colonialismo, a marca mais ou menos implícita, e a forma como aquele poder subsiste até hoje. A colonialidade do poder se apoia em três eixos globalmente articulados: trabalho, raça e gênero (QUIJANO, 1992; 2010, p. 113;). E não é apenas uma divisão global, mas especialmente, uma classificação, em que o homem branco assume o locus (autodeclarado) privilegiado na hierarquia global e as diferenças culturais do resto do mundo em relação à Europa, foram assumidas, segundo a lógica colonial, como desigualdades hierárquicas:

E tais desigualdades são percebidas como de natureza: só a cultura europeia é racional, pode conter "sujeitos". As demais não são racionais. Não podem ser nem almejar "sujeitos". Em consequência, as outras culturas são diferentes no sentido de serem desiguais, de fato inferiores por natureza. Só podem ser "objeto" de conhecimento ou de práticas de dominação. Nessa perspectiva, a relação entre a cultura europeia e as outras culturas se estabeleceu e, desde então, se mantém como uma relação entre “sujeito" e "objeto" (QUIJANO, 1992, p. 16. Tradução nossa ${ }^{4}$ )

É importante destacar que tal dinâmica, na interação entre povos, não é inaugurada com esse "encontro". Observando a história, é possível encontrar outras experiências com traços semelhantes. Nesse sentido, o pensador mexicano Leopoldo Zea publicou nos anos 1980 seu "Discurso desde a criminalização e a barbárie", revelando uma longa tradição de subalternização entre povos. Chegando ao mesmo ponto de reconhecimento de um poder planetário exercido pela racionalidade europeia e mais recentemente deslocado para os Estados Unidos, Zea regressa até a adoção pioneira do epíteto "bárbaro" com o qual eram designados todos os povos que não falavam bem grego: cruelmente, sua humanidade era posta em suspeição por não dominarem uma língua que não era sua. Posteriormente, o horizonte civilizatório é deslocado para os romanos que passam a considerar bárbaros aqueles que vivem

\footnotetext{
${ }^{4} \mathrm{Y}$ tales desigualdades son percibidas como de naturaleza: sólo la cultura europea es racional, puede contener "sujetos". Las demás, no son racionales. No pueden ser o cobijar "sujetos". En consecuencia, las otras culturas son diferentes en el sentido de ser desiguales, de hecho inferiores, por naturaleza. Solo pueden ser" objetos" de conocimiento y/o de prácticas de dominación. En esa perspectiva, la relación entre la cultura europea y las otras culturas, se estableció y desde entonces se mantiene, como una relación entre “sujeto” y “objeto”.
} 
fora da lei, da civitas. E assim sucessivamente, foi se reproduzindo uma dicotomia entre civilização e barbárie, cujo objetivo na verdade sempre foi a sustentação de relações de poder e dependência, ou centro e periferia, onde os povos são destinados à dominação por não serem “cópia exata de seu dominador” (ZEA, 2005, p. 51-52).

O que é inaugurado - e por isso, a periodização proposta por Dussel é tão significativa - é o alcance global e a durabilidade do fenômeno do eurocentrismo, já que coloca a Europa e América do Norte como centro e todo o restante do mundo como periferia, subalternizada e dependente. Nesse sentido, "a globalização é um processo pelo qual determinada condição ou entidade local estende sua influência a todo o globo e, ao fazê-lo, desenvolve a capacidade de designar como local outra condição social ou entidade rival" (SANTOS, 2008, p. 438), no caso do eurocentrismo, tem-se a abstração e universalização dos padrões eurocêntricos, apoiada na particularização e subalternização das demais racionalidades ou modos de realidade.

Esse é o ponto que se pretende demonstrar: essa dinâmica entre centro e periferia, marcada por dominação e dependência, tem de fato longínquos precedentes, mas tem também traços distintivos próprios da modernidade, em especial a adição do trabalho (capitalista, assalariado) aos elementos raça e gênero, como forma de classificação social. Trata-se, atualmente, de um capitalismo eurocentrado, acompanhado por uma lógica de poder que abarca todos os tipos de atividades e formas de conhecimento, exercendo controle sobre a subjetividade e sobre a intersubjetividade humana (QUIJANO, 2010, p. 84-86). Esse padrão repercute numa configuração geopolítica de domínio e exploração, bem como de violação de direitos humanos, que atravessa vários campos das ciências e se ocupa de inúmeros objetos, dentre os quais, as fronteiras internacionais.

Defende-se, portanto, a necessidade de problematizar a partir de uma perspectiva interdisciplinar e descolonial, o tema das migrações, considerando que as fronteiras internacionais são um dos campos estratégicos de conflito e afirmação do poder colonial, ou, afirmação do eurocentrismo. As fronteiras internacionais revelam o epicentro geográfico de um fenômeno fundamentado não apenas no domínio epistemológico, mas também econômico, cultural e ontológico e como tal, constituem-se em locais de exercício de poder. Usualmente esse poder é descrito por meio de uma abstração: a ideia de soberania, entretanto, essa abstração oculta ou dissimula o padrão de poder aqui discutido com base nas ideias de eurocentrismo e colonialidade.

Sob outra perspectiva (não crítica, ao menos, não descolonial), esse poder é reconhecido pelo autor da obra Ética da Imigração, Joseph Carens (2013, p. 225), como "um fato óbvio da 
vida política [de modo que] fronteiras têm guardas e os guardas têm armas" (tradução nossa ${ }^{5}$ ). Obviamente, desnecessária seria a defesa de uma fronteira que ninguém deseja ultrapassar, assim como também é compreensível que mais pessoas desejem ultrapassar as fronteiras que (acreditem) lhes separar de uma "vida melhor". Assim, quanto mais exitosa for a difusão do paradigma $^{6}$, mais visada será a fronteira que o separa da população periférica e, portanto, maior o poder necessário para defendê-la.

Conjugando as teses de Aníbal Quijano e de Enrique Dussel (acompanhados, com algumas variações, por outros teóricos críticos ou descoloniais, como Atílio Boron, Ramón Grosfoguel, Boaventura de Sousa Santos), identifica-se o paradigma hegemônico que define o horizonte civilizatório na atual versão da dicotomia civilização-barbárie, a versão moderna: esse paradigma funda-se em elementos como o sistema capitalista, o individualismo, o liberalismo econômico, a cultura e ciência euro-norte-americana. Nas últimas décadas, esse paradigma foi reduzido ao American way of life, enquanto modelo universal de vida difundido principalmente por meio do cinema de Hollywood e da revista The Reader's Digest, uma publicação lançada na década de 1920 com o intuito de apresentar aos leitores uma síntese fiel das publicações e informações produzidas e difundidas pela mídia norte-americana. A publicação, que era essencialmente definida por valores e princípios daquela sociedade, o americanismo, na década seguinte alcançou âmbito internacional, sendo publicada na Inglaterra. Depois, com tradução para o espanhol, alcançou a América Latina, continente em que teve seu valor subvencionado pelos assinantes norte-americanos, para ampliar o acesso à população mexicana cujo poder aquisitivo constituía um obstáculo à circulação da revista. Justamente a "visão simpática" fornecida pela revista a respeito da vida norte-americana ensejou o projeto de expansão de sua circulação (SCHERER JÚNIOR, 2009, p. 42-48).

Não é coincidência que atualmente, embora se cogite a decadência do modo de vida americano $^{7}$, a fronteira que separa os Estados Unidos e México ${ }^{8}$ seja a mais controversa

\footnotetext{
5 "Borders have guards and the guards have guns. This is an obvious fact of political life"

6 Thomas Kuhn (1997:13) considera “"paradigmas' as realizações científicas universalmente reconhecidas que, durante algum tempo, fornecem problemas e soluções modelares para uma comunidade de praticantes de uma ciência". Mas para uma crítica descolonial, é questionável o "reconhecimento universal" e ainda mais o caráter prescritivo que a hegemonia dos modelos assume.

7 Cf. Silva (2015) que analisa obras cinematográficas como indicativos de um esgotamento do paradigma, aventando crise e decadência moral, evidentes no consumismo, apego às aparências e no esvaziamento de sentido da vida dos norte-americanos.

${ }^{8}$ Segundo informes da Patrulha de Fronteira dos EUA, desde o ano 2000 tem se mantido a tendência de migrantes mexicanos em patamares acima de oitenta por cento. O informe destaca que, embora o movimento migratório tenha diminuído no período da pandemia do COVID-19, segue alarmante o número de mortes por homicídio, abandono e até mesmo suicídio nas redes de contrabando humano. Os dados mais atualizados publicados pelo serviço, informam mais de quatrocentos e cinquenta mil detenções em travessias ilegais na fronteira, isso no ano
} 
existente e a mais emblemática para ilustrar a relação centro-periferia. Não menos contraditórias são as fronteiras europeias, a respeito das quais Dussel (1993, p. 25) recorda: uma superpopulação de pobres e miseráveis da Europa foi enviada ao "Terceiro Mundo" durante a colonização e hoje esse continente fecha suas fronteiras para impedir o regresso.

De modo geral, o debate a respeito das fronteiras internacionais e das migrações, ao menos nos discursos teóricos mais difundidos no Ocidente, ocupam-se de controvérsias superficiais e não contemplam a função colonial que se cumpre por meio do controle de fronteiras. Por exemplo: a principal controvérsia orbita em torno de distintas posições a respeito de abrir ou não as fronteiras para a livre circulação, seguida por controvérsias a respeito de como tratar as migrações motivadas por guerras, perseguições, necessidade de refúgio ${ }^{9}$, culminando ambas na questão das soberanias nacionais. Também de modo geral, esses debates são negligentes com o ponto que abriga o aspecto colonial do tema: as razões de migração.

Embora a saída seja motivada por razões diversas, verifica-se que a entrada tende a ser almejada nos países centrais (europeus e norte-americanos) ${ }^{10}$, porque há um modelo de vida ideal - que é eurocêntrico - e que só pode ser plenamente vivido nesses espaços, mas pode ser aproximadamente vivido nos países que incorporam os valores modernos, pelo quê, são escolhas secundárias. Por isso, na próxima seção, pretende-se destacar como algumas discussões a respeito do tema reforçam essa função colonial, pois dessa forma, pode-se chegar a uma plataforma compreensiva que enseje espaços para descolonização do debate.

\section{CONFLITO ENTRE DIREITO INDIVIDUAL DE MIGRAÇÃO E SOBERANIA ESTATAL SOBRE AS FRONTEIRAS: UM DEBATE EUROCÊNTRICO}

No início dos anos 1990, a filósofa de Budapeste Agnes Heller publicou no jornal El País suas Dez teses sobre a imigração. Propondo uma analogia a remotas regras domésticas,

de 2020, com a diminuição no fluxo, pois no ano de 2019 foram mais de novecentos e setenta mil detenções (UNITED STATES, 2020).

${ }^{9}$ Recentemente o Alto Comissariado das Nações Unidas para os Refugiados (ACNUR) divulgou o relatório anual de tendências globais com dados sobre deslocamento forçado apresentando dados impressionantes, de uma população de quase oitenta milhões de pessoas forçadas a migrar, cerca de um por cento da população mundial, composta em quase metade, por crianças. Esse imenso contingente de migrantes involuntários, embora tenham como razão do deslocamento a procura por condições de produzir e reproduzir sua vida, um dos direitos mais elementares, tem sido recebido por países em desenvolvimento (com acolhimento de cerca de oitenta e cinco por cento), mais precisamente pelos chamados "menos desenvolvidos", que têm recebido quase um terço do total de migrantes forçados, o que acaba alocando cerca de oitenta por cento dessas pessoas em países com grave crise alimentar e desnutrição (ACNUR, 2020a).

${ }^{10}$ No último ano, o maior número de pedidos de refúgio no último ano foi registrado nos Estados Unidos, conforme relatório da ACNUR (2020b, p. 39) e tem três países europeus (Alemanha, França e Espanha) entre os cinco mais procurados por refugiados. 
defendia que emigração é um direito humano, mas a imigração não, afinal, ninguém é obrigado a permitir o ingresso de estranhos em suas casas. Entretanto, essa decisão não é meramente pragmática, definida em função do desconforto que a entrada de estranhos pode provocar aos habitantes de uma casa, mas é também uma decisão moral, de modo que é influenciada, desde os tempos mais remotos, por costumes éticos, como o dever de abrigar necessitados, inocentes perseguidos ou pessoas ameaçadas por perigos mortais.

Tal dilema, segundo Heller, é igual para o Estado. Por isso, defendia leis permissivas à entrada de estrangeiros, desde que esses observassem e cumprissem algumas "regras domésticas", condições básicas para uma vida comum de modo civilizado. Tais regras seriam a) o respeito às leis do país anfitrião, b) o respeito às normas sociais não escritas, como as de higiene e urbanidade e c) a contribuição ao bem-estar, o que se faz por meio do trabalho, conforme suas capacidades (HELLER, 1992).

Essa ideia ilustrada no ensaio de Heller - a ideia de uma relação assimétrica entre os direitos de entrada e saída de territórios - ressoa vivamente até os dias atuais, constituindo talvez o maior embaraço enfrentado nos debates teóricos a respeito da liberdade de movimento. Como bem sintetiza Christopher Wellman (2016), ainda que se possa reconhecer um consenso básico quanto ao direito das pessoas de sair dos países, esse direito estabelece uma relação assimétrica com a prerrogativa dos Estados de recusar a entrada de não nacionais em seus respectivos territórios, o que faz do direito de entrada e saída um direito bastante complexo.

Wellman sistematiza esse direito com base em três principais posições: a defesa de uma relação simétrica na qual as pessoas têm o direito de sair dos Estados e a esse direito corresponde o dever de outros Estados em admitir o ingresso; a defesa de uma posição assimétrica em que as pessoas têm o direito de emigrar, mas nenhum Estado o dever de permitir o ingresso e a defesa de outra posição simétrica, em que não se reconhece o direito de sair de um país, tampouco o dever de admissão de entrada. Em sua análise o autor generaliza o assunto, sem se ater a especificidades como migrações forçadas em razão de guerra ou perseguição, na verdade esboça um cenário hipotético para análise mais compatível com migrações voluntárias.

Em síntese, a tese do filósofo norte-americano é a de que a posição assimétrica entre os direitos de entrar e sair dos Estados tem um poderoso reforço no argumento da liberdade de associação, que por sua vez, pressupõe a possibilidade de recusa à associação: explica o autor que essa liberdade interfere diretamente na autodeterminação, já que o tipo de imigrante que ingressa no país afeta a vida política, econômica e cultural da comunidade nacional e demonstra seu ponto de vista cogitando como a eventual legalização de direitos de voto e cidadania dos 
imigrantes mexicanos poderia determinar leis futuras nos Estados Unidos, inclusive aquelas relativas à imigração.

Em razão disso, sustenta Wellman $(2016,84)$ que "qualquer regime que proteja e respeite satisfatoriamente os direitos humanos tem o direito de elaborar e aplicar unilateralmente sua própria política de imigração" (tradução nossa ${ }^{11}$ ). Sua aposta é problemática não apenas por apresentar uma visão restritiva de direitos humanos ${ }^{12}$, mas também por creditar a esses Estados a capacidade de oportunizar as condições de vida humana digna, de modo que nenhuma pessoa precisaria sair de seus países para viver bem.

Diferente seria a condição das pessoas que vivem em Estados que desrespeitam os direitos humanos, mas nem mesmo para esses o autor reconhece a obrigação de um Estado em abrir suas fronteiras, porque essa não seria a única maneira de ajudar: sugere que o país poderia encontrar outro disposto a aceitar a imigração e então contribuir com uma cota justa em dinheiro. É uma ideia que o autor ilustra numa analogia a crianças órfãs: ninguém tem o dever de adotá-las, mas quem tiver condições econômicas, tem o dever moral de prover ajuda financeiras.

O modo de vida americano, permeia a análise de Wellman, pautando inclusive as analogias que o autor propõe como mediações (casamento, propriedade privada, clubes de golfe, caridade) e define o seu padrão de vida minimamente decente. Ocorre que, como evidencia a crítica descolonial, esse modo de vida só é plenamente possível nos países centrais e não em qualquer Estado, como sugere o autor. Por isso seu discurso não apenas é colonizador, como também insidioso. Inclusive porque para as sociedades periféricas o Estado-nação frequentemente atua como instituição opressora: seja por meio de ações totalitárias e ditatoriais, seja por meio da exclusão do povo dos espaços democráticos e serviços públicos.

David Weissbrodt e Michael Divine (2012, p. 152-176) desenvolvem uma análise mais sensível sobre o tema da migração, já que mais pautada na defesa de direitos humanos e fundamentais. Consignam sua preocupação com as frequentes violações de direitos, exploração, discriminação, riscos de expulsão compulsória, dentre outras formas de exclusão que têm se mostrado ineficazes para diminuir os movimentos migratórios, como bem destacam os autores. Sobre tais premissas, apresentam uma contundente defesa do respeito devido aos não-nacionais

\footnotetext{
11 “[...] any regime which satisfactorily protects and respects human rights is entitled to unilaterally design and enforce its own immigration policy"

12 Especifica-os como reivindicações de proteção contra ameaças a uma vida minimamente decente, o que passa por condições como como educação, religião, sustento para a família etc. É uma perspectiva reducionista porque, por mais bem-intencionada que seja a ideia a respeito dos direitos humanos, qualquer prescrição material desses será restritiva, já que as sociedades humanas têm aspirações diversificadas.
} 
e aos seus direitos, inclusive o direito de entrar e sair dos territórios. É interessante como a análise problematiza a dicotomia, que remonta aos tempos mais longínquos na história, entre nacionais e estrangeiros, ou civilizados e bárbaros (dicotomia mais acentuada na crítica de Leopoldo Zea) e as distintas formas como os Estados contemporâneos tratam o tema: variando desde posturas protecionistas, que ampliam os direitos internacionalmente reconhecidos aos imigrantes, até a adoção de medidas discriminatórias e violações de direitos (situação que muitas vezes os imigrantes são obrigados a suportar em silêncio, por medo de deportação).

Após essa análise (mais empática) que reconhece o abismo entre direitos formalmente enunciados e a realidade das vidas dos imigrantes, Weissbrodt e Divine propõem alguns mecanismos de prevenção contra violações de direitos humanos: o reconhecimento de tratados, direito nacional, apoio de organizações internacionais e da assistência consular. Em todo caso, reconhecendo a responsabilidade e função principais dos governos no assunto, o que reconduz ao problema já apontado dos limites da institucionalidade estatal.

Da mesma forma, a análise dos autores não enfrenta a questão da colonialidade, por isso subestima a hierarquização subjacente à relação entre civilização e barbárie ou nacionais e estrangeiros. Enquanto tal questão não for devidamente tratada, subsistirão controvérsias em torno das migrações, obstáculos ao reconhecimento de um genuíno direito de mobilidade global e subsistirão também os meios e as justificações da coerção exercida pelos Estados.

Joseph Carens (2013, p. 225-228; 256) apresenta uma perplexidade diante desse poder, uma problematização a respeito do porquê de usar a força contra pessoas pacíficas que apenas procuram a oportunidade de uma vida melhor. Para o autor, todos os seres humanos possuem igual valor, por isso, restringir sua liberdade exige uma justificação moral e tal justificação não pode ser simplesmente deduzida da soberania. Carens refuta as principais alegações em defesa do domínio sobre as fronteiras, tais como os custos gerados para os cidadãos, que não passam de uma visão limitada da justiça, e defende as fronteiras abertas, pois considera a liberdade de movimento essencial para a igualdade de oportunidades. $\mathrm{O}$ acesso a melhores oportunidades deve ser franqueado aos méritos de cada pessoa:

Nos Estados democráticos, todos nós reconhecemos, ao menos em princípio, que o acesso a posições sociais deve ser determinado pelos talentos e esforços reais de um indivíduo e não limitados com base em características relacionadas ao parto, como classe, raça ou gênero, que não são relevantes à capacidade de um bom 
desempenho na posição (CARENS, 2013, p. 227. Tradução nossa ${ }^{13}$. Sem grifo no original).

Aparentemente, o que o autor ignora é que a sua própria visão de justiça é limitada. Ao afirmar que classe, raça ou gênero são irrelevantes à capacidade de um bom desempenho, Carens materializa o discurso eurocêntrico e evidencia o lugar de fala do homem branco norteamericano ou europeu: o sujeito que pode receber irrestritamente o reconhecimento por seus méritos, pois é parte de uma parcela pequena da humanidade que não sofre os efeitos da colonialidade: não sofre a discriminação racial, não sofre a opressão patriarcal e não sofre a exploração no trabalho.

Será que os imigrantes mexicanos que vivem, clandestinamente ou não, nos Estados Unidos concordam que abrir as fronteiras é suficiente para que tenham uma vida melhor? $\mathrm{Ou}$ os imigrantes latino-americanos, africanos, asiáticos que vivem na Europa ou na América do Norte? Para os corpos periféricos - o corpo feminino, o corpo negro, o corpo índio, o corpo pobre e tantos outros - classe, raça e gênero são muito relevantes: não para definir a capacidade, mas porque definirão os óbices - às vezes intransponíveis - aos seus talentos. A corporeidade tem relevância porque é o corpo que sofre a dominação de gênero, de raça ou qualquer forma de dominação (QUIJANO, 2010, p. 127).

Catástrofes, miséria, pobreza, guerras, perseguições políticas, religiosas, étnicas entre outras, são as evidências mais contundentes de que o lugar de nascimento é um fator importante para cada ser humano. Mas é justo questionar se é o mais importante deles, pois simultaneamente a tais condições objetivas, projeta-se um horizonte universal, um horizonte eurocêntrico, nos limites do qual, parece não haver possibilidades de desenvolvimento para os povos e nações periféricos.

\section{PERSPECTIVAS DESCOLONIAIS SOBRE O DIREITO DE MIGRAR}

O jurista espanhol Joaquín Herrera Flores (2002) propõe uma "racionalidade de resistência” ao pensar a questão dos direitos humanos e a aplica aos diversos temas que a ideia abarca. Já foi mencionado o horizonte construído na modernidade, mas Herrera Flores apresenta uma crítica precisa ao defini-lo como universalismo de partida ou universalismo a priori e, enfrentando a complexa dimensão do eurocentrismo (ainda que sem mencioná-lo

13 Within democratic states we all recognize, at least in principle, that access to social positions should be determined by an individual's actual talents and effort and not limited on the basis of birth-related characteristics such as class, race, or gender that are not relevant to the capacity to perform well in the position 
expressamente), consegue perceber também a dinâmica de dominação, exploração e discriminação que essa ideia sustenta.

E sensível à realidade de imigrantes, subverte seu próprio "lugar de fala" de homem branco europeu, denunciando como países que recepcionam "mandam" em imigrantes que, por serem diferentes, desiguais, "servem", numa relação negligente com a "tragédia pessoal de milhões de pessoas que fogem do empobrecimento de seus Países, em razão da rapina indiscriminada do capitalismo globalizado" (HERRERA FLORES, 2002, p. 11). Claro que para se encontrar nessa condição, o imigrante precisa conseguir transpor a fronteira e ingressar no território, desafio que pode ser mais árduo, a depender de qual fronteira, segundo se tem sustentado desde a primeira seção.

Tipo de situação que fica evidente em casos como o mencionado por Herrera Flores que prossegue formulando uma crítica às autoridades da União Europeia (crítica que bem cabe às autoridades norte-americanas), que adotam postura beligerante diante da imigração ilegal, construindo uma "Europa-Fortaleza" que ainda protege seus interesses explorando suas antigas colônias e oculta o abismo que separa nações ricas e pobres e desconsidera a causa da imigração: as "injustiças da globalização neoliberal selvagem”.

Ainda é atual a crítica que Freud formulou na primeira metade do século XX em $O$ malestar na civilização, evidenciando a armadilha que a marcha do progresso preparou para a humanidade, porque não apenas denunciou o elevado custo do mito civilizatório - todas as renúncias e sacrifícios impostos ao indivíduo, a negação de sua própria natureza ou essência em favor da "compulsão ao trabalho" - como também evidenciou sua consequência e maior risco, visto que "os seres humanos atingiram um tal controle das forças da natureza, que não lhes é difícil recorrerem a elas para exterminarem até o último homem [...] daí em boa parte, o seu atual desassossego, sua infelicidade, seu medo" (FREUD, 2011, p. 93).

A distribuição geopolítica do progresso da modernidade é explicada por Boaventura de Sousa Santos (2010, p. 31-34) a partir da ideia de "pensamento abissal", que se manifesta como sistema segundo o qual a realidade é dividida radicalmente (não é possível estar dos dois lados) por uma "linha": de um lado, o que é visível, do outro, o que é invisível, ou, sequer existe como realidade, como as sociedades metropolitanas e os territórios coloniais (que remonta a linha global que separava o Novo do Velho Mundo), respectivamente. As duas melhores elaborações dessa linha abissal são o conhecimento (fundado no monopólio das formas científicas de verdade) e o direito (em que legal e ilegal são as únicas formas relevantes de existência). Como as sociedades periféricas estão "do outro lado da linha", estão além do conhecimento verdadeiro 
ou falso, ou seja, sequer têm existência relevante ou comensurável, assim como, para o direito, são “território sem lei”.

\begin{abstract}
A modernidade ocidental, em vez de significar o abandono do estado de natureza e a passagem à sociedade civil, significa a coexistência da sociedade civil com o estado de natureza, separados por uma linha abissal com base na qual o olhar hegemônico, localizado na sociedade civil, deixa de ver e declara efetivamente como não existente o estado de natureza (SANTOS, 2010, p. 36-37).
\end{abstract}

Com essa dissimulação - o fingimento de que o real não existe (BAUDRILLARD, 1991), as sociedades civilizadas evitam seu mal-estar. A subsistência dessa dicotomia entre civilização e barbárie, funciona como a linha invisível além da qual direitos humanos não são violados, porque sequer se aplicam - são espaços impensáveis para a lei ou para os direitos humanos (SANTOS, 2010, p. 39); essa linha invisível permite, por exemplo, a divisão internacional do trabalho (MARINI, 1976), na qual as populações periféricas assumem etapas inferiores da produção, enquanto o capitalismo central avança. Mas não é apenas isso: essas populações seguem gastando seus corpos nas minas, suportando o trabalho escravo e a exploração do trabalho infantil. Essa relação global entre centro e periferia põe em questão a possibilidade de uma universalização de oportunidades, isso porque

Analisando-se a chamada "crise de refugiados" que acontece principalmente na Europa fica claro que tal universalidade não vale para todas as pessoas, uma vez que para conseguir escapar de uma situação insuportável no lugar em que vivem, os sujeitos precisam entrar de forma ilegal no país em que buscam refúgio (FAGUNDES; SPAREMBERGER; LOCH, 2018, p. 365).

Wellmann (2016, p. 88) avalia que os Estados existentes atualmente são suficientemente grandes e permissivos quanto à migração, e por isso, aptos a assegurar a liberdade de movimento. É um dos argumentos que o autor apresenta para fundamentar a defesa de uma relação assimétrica em que não corresponde ao direito de emigrar - o qual não questiona - um direito de imigrar - o qual não reconhece, pois considera, como já observado, que a autodeterminação e a liberdade de associação asseguram a qualquer Estado o direito de recusar ingresso de estrangeiros. Para o autor, os Estados têm extensão suficiente para assegurar às pessoas o acesso a oportunidades sem necessidade de sair de seu país.

Já para Milton Santos, um teórico crítico, periférico em relação às epistemologias eurocêntricas, a migração comporta outros sentidos. Santos considera injusto condenar os indivíduos à imobilidade. Nisso convergem ambos os autores. Mas para o geógrafo latinoamericano, negro, vítima de exílio imposto pelo regime militar, também é injusto forçar a 
migração. Questiona a respeito das "vicissitudes, verdadeiramente dramáticas, que afligem uma parcela significativa da população, em busca permanente e sem sucesso de terra para plantar no interior e de terra para morar na cidade" (SANTOS, 2007, p. 60).

Bem, o Brasil é um país de destacada extensão territorial e desde os anos 1980, é, formalmente, um Estado democrático e de direitos. Porque, na fórmula abstrata de Wellman, tem todos os pressupostos para assegurar a liberdade dos indivíduos, mas para Milton Santos não o tem? O corpo do segundo viveu a experiência; o do primeiro, não compartilha as mesmas vicissitudes cotidianas, pois está do lado visível da linha. Por isso Milton Santos (2007, p. 6061) foi capaz de perceber no Brasil movimentos que definiu como "verdadeiras migrações forçadas", forçadas pelo mercado, forçadas pela ausência de bens e serviços essenciais. Mas as migrações não asseguram a essas pessoas o acesso as oportunidades, antes, fazem vítimas que o país bem conhece: boias-frias migrando no interior quando a safra precisa de mão-de-obra, boias-frias nas cidades.

O Brasil, que está do outro "lado da linha" em relação às sociedades centrais (Estados Unidos, sociedades europeias), cria sua própria linha abissal e trata como estrangeiros indesejáveis, como imigrantes clandestinos, o seu próprio povo ${ }^{14}$. E assim, reproduz internamente o tipo de tratamento que aquelas sociedades reservam ao "regresso do colonial" (SANTOS, 2010, p. 42), entre os quais, o imigrante: exploração, criminalização, discriminação. A necessidade de uma perspectiva descolonial sobre o direito à migração se impõe não apenas como questionamento ao eurocentrismo, mas também como estranhamento diante da abstração negligente dos complexos desdobramentos do tema, que não podem ser resolvidos no âmbito de uma discussão sobre soberania e segurança nacional, mas que reivindicam, como postulam Fagundes, Sparemberger e Loch (2018, p. 367; 370), "outro olhar", transcendendo a usual lógica utilitarista dos Estados neoliberais, e reconhecendo o "migrante como sujeito de direitos".

Como convoca Herrera Flores (2001, p. 25), é necessário resistir à compreensão da imigração como fonte de problemas sociais, resistir à justificação da superioridade da segurança

14 É importante destacar que, a despeito de sua notória reputação como país "hospitaleiro" e dos princípios fundamentais de suas relações internacionais (notadamente a prevalência dos direitos humanos e numa interpretação extensiva, a concessão de refúgio como correlata à concessão de asilo político), difundiu-se no Brasil nos anos recentes um discurso hostil também em relação a imigrantes estrangeiros. Isso coincidiu com uma mudança no cenário político e com o momento em que o país vizinho, Venezuela, mergulhou numa grave crise, levando mais de quatro milhões de pessoas a deslocarem-se do país, das quais mais de duzentas e sessenta mil foram recebidas no Brasil, considerado o quinto maior anfitrião do país vizinho (ACNUR, 2020b). 
em detrimento dos direitos humanos, não converter o imigrante em "bode expiatório" dos desafios e incapacidades de uma nação.

\section{CONSIDERAÇÕES FINAIS}

Sobre os aportes teóricos apresentados na primeira e segunda seção, buscou-se construir uma plataforma reflexivo-crítica para analisar a questão das migrações. O intuito foi demonstrar que o poder soberano e o controle (coercitivo) de entrada e saída dos Estados estão associados à colonialidade, enquanto dinâmica global de hierarquização das sociedades modernas, na qual, há o domínio ontológico, epistemológico e político de umas poucas nações sobre todas as demais. Em função dessa hierarquização, as fronteiras europeias e norte-americana consolidamse como as mais almejadas - e mais defendidas - do globo, porque o fenômeno que se apoia na colonialidade é o eurocentrismo.

Todavia, esse aspecto não é contemplado no campo teórico e conceitual dos direitos humanos e migrações e os principais autores que têm militado nesse campo, expressam posturas e valores de modo a reforçar o eurocentrismo. A superficialidade com que o tema é tratado dificulta processos de solidariedade entre nações e Estados diante das tragédias que obrigam inúmeros fluxos migratórios, da mesma forma como se nota a ausência de empatia com o sentimento de incompletude e insatisfação que sociedades periféricas experimentam por estarem impossibilitadas de materializar o paradigma civilizatório vigente, o dito sonho americano, esse ethos (valores modernos como liberdade econômica, individualismo, meritocracia entre outros) que é amiúde reforçado nas mais variadas teorias a respeito da relação entre direitos humanos, migração e soberania sobre as fronteiras.

Tal relação, estranhada por uma perspectiva descolonial, revela que a abstração do conceito de soberania, naturaliza a forma como os países vem exercendo o controle sobre suas fronteiras mediante a seleção de imigrantes, de modo que o paradoxo entre migração e soberania nacional é apenas aparente: a soberania nacional é fundamento não para limitação do direito de ingresso nos países, mas para impedir o ingresso dos indesejáveis. Porque há um perfil de ser humano, eurocentricamente definido e nos termos da colonialidade, que não enfrenta tais vicissitudes.

Por isso, defende-se a necessidade de expandir o horizonte compreensivo das razões e propósitos das migrações e seu correspondente direito de ingresso nos países. A civilização pode trazer o fardo do sofrimento e da culpa, como explica Freud, pode ser um simulacro, mera ilusão, como explica Baudrillard, mas é também o desejo de parcelas cada vez mais abrangentes 
da humanidade, porque do sucesso na difusão do paradigma hegemônico, decorre a frustração da periferia, por não poder reproduzi-lo. Fora do domínio eurocêntrico, nem mesmo os simulacros são possíveis. Isso faz com que, para quem migra, o desafio ao poder coercitivo das fronteiras expondo a riscos a própria vida valha a pena, pois é o meio para alcançar o lugar das oportunidades, das possibilidades infinitas.

O intuito desse estudo foi demonstrar a ausência na consideração de elementos epistemológicos e ontológicos que se acrescentam à dimensão jurídica relativa aos direitos humanos e à soberania. Considera-se que, a partir desses elementos, é possível fundamentar a responsabilidade das nações centrais diante dos desejos e movimentos de migração, assumindo que tais movimentos são, simultaneamente aos diversos outros fatores que os originam, respostas a paradigmas eurocentricamente definidos e que assumem força prescritiva sobre modos de realidade e, por isso, o controle sobre as fronteiras internacionais não é mero exercício de soberania, é sobretudo, um campo de exercício de poder colonial.

\section{REFERÊNCIAS BIBLIOGRÁFICAS}

ACNUR. Alto Comissariado das Nações Unidas para os Refugiados. GLOBAL TRENDS: forced displacement in 2019. 18 jun. 2020a. Disponível em:

https://www.unhcr.org/5ee200e37.pdf . Acesso em: 30 out. 2020.

ACNUR. Alto Comissariado das Nações Unidas para os Refugiados. Venezuelans in Brazil: integration with labour market and access to social safety nets. 2020b. Disponível em: https://www.acnur.org/portugues/wp-content/uploads/2020/07/Estudo-sobreIntegra\%C3\%A7\%C3\% A3o-de-Refugiados-e-Migrantes-da-Venezuela-no-BrasilENGLISH.pdf . Acesso em: 30 out. 2020.

BAUDRILLARD, Jean. Simulacros e simulação. Lisboa: Relógio D’Água, 1991.

BORON, Atilio A. Aristóteles em Macondo: notas sobre el fetichismo democrático em América Latina. Córdoba: Espartaco Córdoba, 2009.

CARENS, Joseph H. The ethics of immigrations. Oxford: Oxford University Press, 2013.

DUSSEL, Enrique. 1492: o encobrimento do outro: a origem do mito da modernidade, conferências de Frankfurt. Petrópolis: Vozes, 1993.

DUSSEL, Enrique. Ética da libertação: na idade da globalização e da exclusão. 4. Ed. Rio de Janeiro: Vozes, 2012.

FAGUNDES, Lucas Machado; SPAREMBERGER, Raquel Fabiana Lopes; LOCH, Andriw Souza. O utilitarismo na política migratória brasileira: a luta por direitos humanos dos migrantes. Revista Direitos Culturais, v. 13, n. 31, pp. 355-377, 2018. Disponível em: 
http://srvapp2s.urisan.tche.br/seer/index.php/direitosculturais/article/view/2871/1580 . Acesso em: 27 out. 2020.

FREUD, Sigmund. O mal-estar na civilização. São Paulo: Penguin Classics, Companhia das Letras, 2011.

GROSFOGUEL, Ramon. "Para descolonizar os estudos de economia política e os estudos pós-coloniais: transmodernidade, pensamento de fronteira e colonialidade global." in SANTOS, Boaventura de Sousa. MENESES, Maria Paula. Epistemologias do Sul. São Paulo: Cortez. pp. 455-491, 2010.

HELLER, Agnes. Diez tesis sobre la inmigración. El País, 1992. Disponível em: https://elpais.com/diario/1992/05/30/opinion/707176809_850215.html . Acesso em: 27 out. 2020.

HERRERA FLORES, Joaquín. Direitos humanos, interculturalidade e racionalidade de resistência. Revista Sequência, Florianópolis, v. 23, n. 44, pp. 9-30, 2002. Disponível em: http://periodicos.ufsc.br/index.php/sequencia/article/view/15330/13921 . Acesso em: 27 out. 2020.

KUHN, Thomas S. A estrutura das revoluções científicas. 5 ed. São Paulo: Perspectiva, 1997.

MARINI, Ruy Mauro. Dialética da dependência. Coimbra: Centelho, 1976.

O’GORMAN, Edmundo. A invenção da América: reflexão a respeito da estrutura histórica do Novo Mundo e do sentido do seu devir. São Paulo: Editora da Universidade Estadual Paulista, 1992.

QUIJANO, Aníbal. Colonialidade e Modernidade/Racionalidade. Peru Indígena, v. 13, n. 29, p. 11-20, 1992. Disponível em: http://www.lavaca.org/wpcontent/uploads/2016/04/quijano.pdf . Acesso em: 27 out. 2020.

QUIJANO, Aníbal. Colonialidad del poder, globalización y democracia, Lima, dez. 2000 Disponível em: http://rrojasdatabank.info/pfpc/quijan02.pdf . Acesso em: 27 out. 2020.

QUIJANO, Aníbal. Dom Quixote e os moinhos de vento na América Latina. Estudos Avançados, v. 19, n. 55, São Paulo, set./dez. 2005. Disponível em: https://www.scielo.br/pdf/ea/v19n55/01.pdf . Acesso em: 27 out. 2020.

QUIJANO, Aníbal. “Colonialidade do poder e classificação social.” in: SANTOS, Boaventura de Sousa. MENESES, Maria Paula. Epistemologias do Sul. São Paulo, 2010, pp. 84-130.

SANTOS, Milton. O espaço do cidadão. 7 ed. São Paulo: Editora da Universidade de São Paulo, 2007.

SANTOS, Boaventura de Sousa. "Para além do pensamento abissal: das linhas globais a uma ecologia de saberes." in: SANTOS, Boaventura de Sousa. MENESES, Maria Paula.

Epistemologias do Sul. São Paulo, 2010, pp. 31-83. 
SANTOS, Boaventura de Sousa. A gramática do tempo: para uma nova cultura política. 2 ed. São Paulo: Cortez, 2008.

SCHERER JÚNIOR, Charles. A revista Selecciones del Reader's Digest e a constituição da imagem dos estereótipos do american way of life: 1940/1950. 207 f. Tese (Doutorado em História) - PUCRS, Fac. de Filosofia e Ciências Humanas. Porto Alegre, 2009. Disponível em: http://repositorio.pucrs.br/dspace/handle/10923/3754 . Acesso em: 27 out. 2020.

SILVA, Vitáli Marques Corrêa da. A decadência moral do american way of life vista por Hollywood: uma análise crítica dos filmes "Beleza Americana" e "Clube da Luta". Revista Contraponto, v. 2, n. 1, 2015. Disponível em: http://seer.ufrgs.br/index.php/contraponto/ article/view/54390/33251. Acesso em: 27 out. 2020.

UNITED STATES (U.S.). U.S. Customs and Border Protection. Unidentified Migrant Remains Increase at U.S./Mexico Border. 30 out. 2020. Disponível em: https://www.cbp.gov/newsroom/national-media-release/unidentified-migrant-remainsincrease-usmexico-border . Acesso em 1 nov. 2020.

WEISSBRODT, David; DIVINE, Michael. "International human rights of migrants." in: B. Opeskin, R. Perruchoud; J. Redpath-Cross (Eds.), Foundations of International Migration Law. Cambridge: Cambridge University Press, 2012, pp. 152-176.

WELLMAN, Christopher Heath. "Freedom of movement and the rights to enter and exit." in: YPI, Sarah Fine and Lea. Migration in Political Theory: The Ethics of Movement and Membership. Oxford: Oxford University Press, 2016, pp. 80-101.

ZEA, Leopoldo. Discurso desde a marginalização e a barbárie; seguido de A filosofia latinoamericana como filosofia pura e simplesmente. Rio de Janeiro: Garamond, 2005. 